\title{
Urocortin, a CRF-like peptide, restores key indicators of damage in the substantia nigra in a neuroinflammatory model of Parkinson's disease
}

\author{
Amjad Abuirmeileh ${ }^{1}$, Alexander Harkavyi ${ }^{1}$, Rebecca Lever ${ }^{1}$, \\ Christopher S Biggs ${ }^{2}$ and Peter S Whitton*1
}

Address: ${ }^{1}$ Department of Pharmacology, The School of Pharmacy, 29-39 Brunswick Square, London WC1N 1AX, UK and ${ }^{2}$ School of Biosciences, University of Westminster, 115 New Cavendish Street, London W1W 6UW, UK

Email: Amjad Abuirmeileh - amjad.abuirmeileh@pharmacy.ac.uk; Alexander Harkavyi - alex.hakavyi@pharmacy.ac.uk; Rebecca Lever - rebecca.lever@pharmacy.ac.uk; Christopher S Biggs - c.biggs@westminster.ac.uk;

Peter S Whitton* - peter.whitton@pharmacy.ac.uk

* Corresponding author

Published: 21 July 2007

Journal of Neuroinflammation 2007, 4:19 doi:10.1186/1742-2094-4-19
Received: 19 April 2007

Accepted: 21 July 2007

This article is available from: http://www.jneuroinflammation.com/content/4/1/19

(C) 2007 Abuirmeileh et al; licensee BioMed Central Ltd.

This is an Open Access article distributed under the terms of the Creative Commons Attribution License (http://creativecommons.org/licenses/by/2.0), which permits unrestricted use, distribution, and reproduction in any medium, provided the original work is properly cited.

\begin{abstract}
We have recently observed that the corticotrophin releasing hormone (CRF) related peptide urocortin (UCN) reverses key features of nigrostriatal damage in the hemiparkinsonian 6hydroxydopamine lesioned rat. Here we have studied whether similar effects are also evident in the lipopolysaccaride (LPS) neuroinflammatory paradigm of Parkinson's disease (PD). To do this we have measured restoration of normal motor behaviour, retention of nigral dopamine (DA) and also tyrosine hydroxylase (TH) activity. Fourteen days following intranigral injections of LPS and UCN, rats showed only modest circling after DA receptor stimulation with apomorphine, in contrast to those given LPS and vehicle where circling was pronounced. In separate experiments, rats received UCN seven days following LPS, and here apomorphine challenge caused near identical circling intensity to those that received LPS and UCN concomitantly. In a similar and consistent manner with the preservation of motor function, UCN 'protected' the nigra from both DA depletion and loss of TH activity, indicating preservation of DA cells. The effects of UCN were antagonised by the non-selective CRF receptor antagonist $\alpha$-helical CRF and were not replicated by the selective $\mathrm{CRF}_{2}$ ligand $\mathrm{UCN}$ III. This suggests that $\mathrm{UCN}$ is acting via $\mathrm{CRF}_{\text {, }}$ receptors, which have been shown to be anti-inflammatory in the periphery. Our data therefore indicate that UCN is capable of maintaining adequate nigrostriatal function in vivo, via $C F_{\text {, }}$ receptors following a neuroinflammatory challenge. This has potential therapeutic implications in PD.
\end{abstract}

\section{Findings}

Parkinson's disease (PD) is largely the result of a degeneration of nigrostriatal neurons. Before the disease presents clinically, death of dopamine (DA) neurons occurs in the substantia nigra pars compacta (SNc) asymptomatically. This has traditionally been ascribed to concurrent apop- totic, excitotoxic and free-radical mediated events $[1,2]$ Recent evidence suggests that both pre- and postnatal neuroinflammation may play a crucial predisposing or causative role in the aetiology of PD $[3,4]$. Prevention of nigrostriatal neuronal destruction once established, or prior to lesion development, represents an ideal future 
therapeutic goal in PD. Urocortin (UCN), a corticotrophin releasing hormone (CRF) related peptide has recently been proposed as a cytoprotectant. Evidence for this exists in a range of tissues including neuronal cells $[5,6]$. Interestingly $\mathrm{UCN}$, acting via $\mathrm{CRF}_{1}$ receptors, is antiinflammatory in the periphery [7]. We have recently observed that UCN arrests the development of Parkinsonian like features in the 6-hyroxydopamine lesioned hemiparkinsonian rat [8]. UCN substantially reverses apomorphine-induced circling, loss of tissue DA, loss of nigral and striatal tyrosine hydroxylase (TH) activity and loss of TH protein levels [8]. Although the 6-OHDA model of PD is well established it has significant physiological limitations. In contrast, lipopolysaccaride (LPS) is an established product of bacterial infection, including relatively common conditions such as bacterial vaginitis. Significantly, evidence suggests that systemic inflammation can predispose or be causative in the genesis of PD $[3,4]$. Therefore, exposure to conditions leading to neuroinflammation, a condition to which the SNc in particularly susceptible, constitutes a realistic mechanism by which the disease may be initiated. Here we have investigated the potential protective effects of UCN in the LPS paradigm of PD. Additionally, we have studied the effects of the non-selective CRF receptor antagonist $\alpha$-helical CRF and also urocortin III (UCN III), a selective $\mathrm{CRF}_{2}$ agonist [9], on indices of nigral DA neuronal integrity to determine whether effects of UCN are receptor mediated and the likely subtype.

UCN, UCN III, LPS, $\alpha$-helical CRF and apomorphine were all obtained from Sigma, UK. The latter agent was dissolved in $0.2 \% \mathrm{w} / \mathrm{v}$ ascorbic acid, whilst LPS, $\alpha$-helical CRF, UCN and UCN III were initially dissolved in water and further diluted in saline. The concentration of UCN chosen is identical to that used in previous investigations $[8,10,11]$. Apomorphine was injected in a volume of 0.1 $\mathrm{ml}$ per $100 \mathrm{~g}$ body weight. Experiments were performed in accordance with the Animals (Scientific Procedures) Act, UK (1986). Male Wistar rats (Charles River, UK; 210-240 g) were group housed with food and water ad libitum. Animals were anaesthetised, secured in a stereotaxic frame and given injections of LPS $(2 \mu \mathrm{g} / 2 \mu \mathrm{l})$ into SNc (from bregma in mm; A -5.2, L 2.2 and V 8.3). Animals cotreated with UCN, UCN III or $\alpha$-helical CRF received injections $(20 \mathrm{fmols} / 2 \mu \mathrm{l})$ directly into the ipsilateral SNc whereas those not receiving UCN were given vehicle. UCN itself was administered either concomitantly with LPS or 7 days later (i.e. once lesions were clearly evident; Fig. 1). All intracerebral injections were performed using a stereotaxic frame mounted microsyringe (Hamilton, US) over approximately four minutes $(0.5 \mu \mathrm{l} / \mathrm{min}$.) and the needle left in place for five min post-injection. Fourteen days after toxin administration (seven days in certain experiments, Fig. 1) rats were given apomorphine (0.5 $\mathrm{mg} / \mathrm{kg}$, s.c.) and rotations measured $30 \mathrm{~min}$ later for 2 min in a circular 'arena', approximately 1 metre in diameter, to estimate lesion severity. Rats were then lightly anaesthetised, brains removed and their substantia nigra dissected on ice. DA was estimated as previously described [12] and TH activity estimated as outlined previously [8]. Data were subjected to one way ANOVA with a post hoc Dunnett's test.

Rats treated with LPS and vehicle displayed characteristic intense, 'tight' contraversive circling, following apomorphine (Fig 1) while those co-treated with intracerebral UCN displayed much reduced apomorphine sensitivity. UCN III did not attenuate apomorphine-induced circling in lesioned rats (Fig 1). LPS treatment produced drastic decreases in nigral DA which were substantially attenuated when UCN was injected at the same time as the LPS (Fig. 1) and critically, when UCN was given seven days following LPS injection. A similar pattern of reduction was seen in nigral TH activity following LPS, and this was also reversed by UCN either given at the same time and also seven days post LPS injection (Fig. 1). In none of the experiments did UCN III effect any decrease in LPSinduced loss of tissue DA or TH activity. In order to establish whether these apparent reductions in 'Parkinsonianlike' pathology were mediated by CRF receptors we coadministered LPS and UCN with the non-selective CRF receptor antagonist, $\alpha$-helical CRF. $\alpha$-helical CRF reversed the 'protective' effects of UCN against LPS-induced loss of DA, TH activity as well as apomorphine-induced circling (Fig. 1). This clearly indicates that CRF receptors mediate the actions of UCN. However, the $\mathrm{CRF}_{2}$ selective analogue of UCN, UCN III was without effect. This logically indicates that the protective actions of UCN are mediated by $\mathrm{CRF}_{1}$ receptors.

The current findings demonstrate that UCN greatly attenuates the development of PD-like pathology in a recently proposed $[3,4]$ paradigm of the illness (LPS). The validity of this model is being increasingly appreciated as the role of neuroinflammation as a factor in the aetiology of PD is gaining substantive support in patients and animal-models $[3,4,13]$. The ability to restore these indices of PD-like damage in dopaminergic nigral neurons seven days after administration of LPS is particularly significant. We have determined that at this time point in our models the lesion has become established but is evidently still unstable since degeneration continues to proceed for a least a further seven days $[8,14]$, Fig. 1 . This is reasonably analogous to the predicament of PD patients, where degeneration proceeds until the nigrostriatal system is to all intents destroyed as the illness reaches its terminal phase. Current treatments are of limited, and purely symptomatic value, becoming ineffective as the neurodegeneration proceeds. What is clearly required is some treatment strategy which 

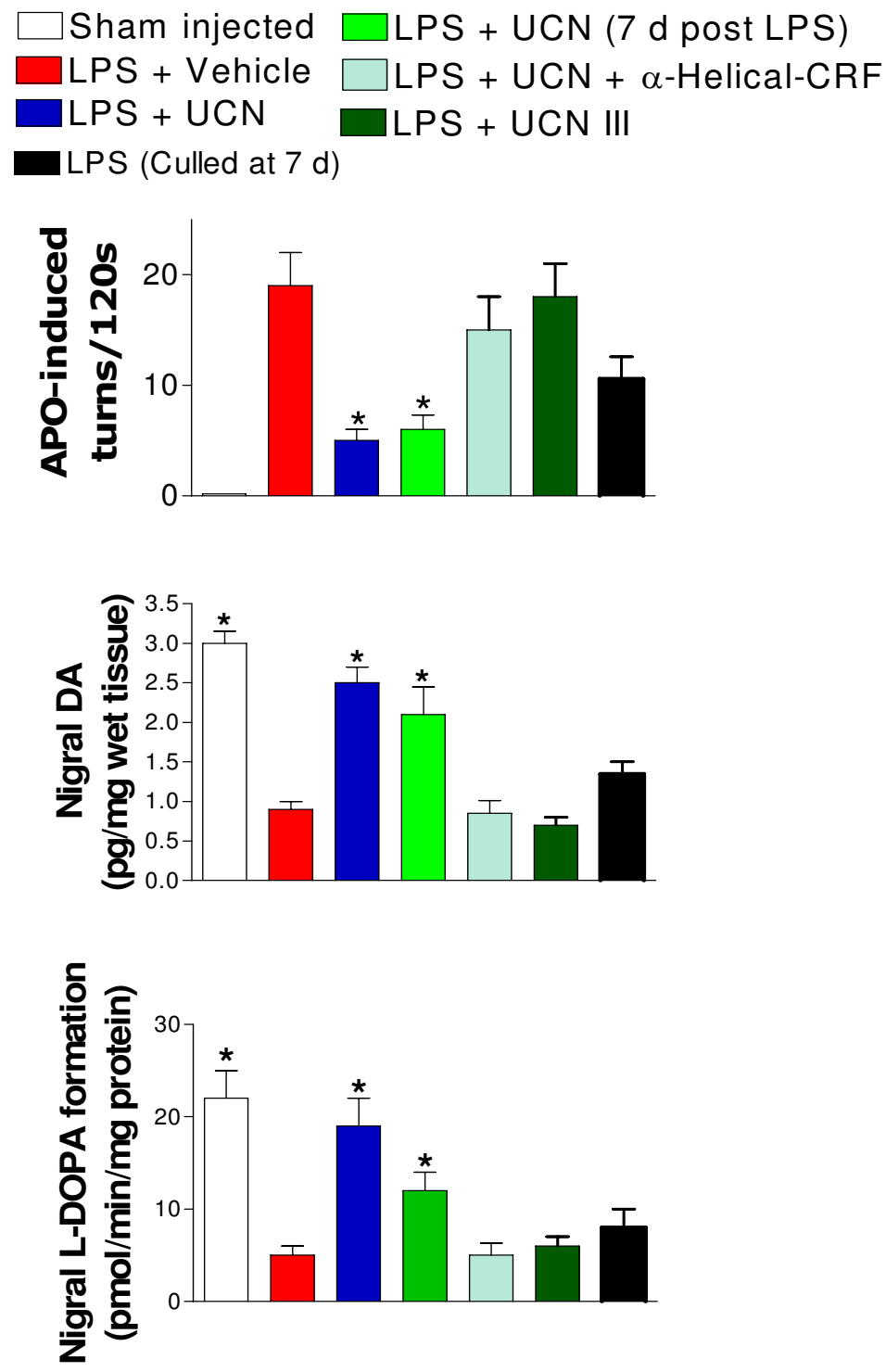

\section{Figure I}

Effect of the CRF-like peptide UCN on indices of nigrostriatal damage induced by intranigral injection of LPS. Data were taken from rats 14 days after injection of LPS and UCN except where indicated (7 d post LPS) in which case UCN was given seven days after LPS injection. In some experiments rats were culled seven days after administration of LPS alone to indicate the development of lesion severity at this point. Indices assessed were as follows: upper panel, circling behaviour in response to the DA agonist apomorphine (one way ANOVA $F=7.763$, $\mathrm{p}<0.00 \mathrm{I}$ ); middle panel, nigral tissue DA concentration $(\mathrm{F}=22.77$, $p<0.001)$, lower panel, nigral tissue TH activity $(F=11.47, p<0.00 I)$. Each group comprised 6-8 rats. In each case differences between groups were assessed using Bonferonni's multiple comparison test. $*_{p}<0.05$ versus groups treated with either LPS and vehicle or LPS and UCN III. 
either stabilizes the hostile conditions prevailing within the SNc, or better, effects some degree of neuronal restoration. Our data suggest that UCN may be able to achieve this, probably acting via $\mathrm{CRF}_{1}$ sites. The observations with UCN suggest that under neuroinflammatory conditions it is able to elicit a functional recovery in nigrostriatal neurotransmission. We have previously found UCN I to be effective in restoring both striatal TH activity and DA content following either LPS or 6-OHDA-induced lesions $[8,14]$. Futhermore, we have found that UCN I also reverses loss of extracellular DA in the striatum of freely moving rats (unpublished data). The resulting recovery in nigral DA neurons presumably allows for a restoration of $\mathrm{D}_{1}$ and $\mathrm{D}_{2}$ receptor balance in the striatum which would logically underlie the recovery in 'normal' motor activity (loss of circling) seen after apomorphine treatment. However, a determination of actual DA receptor population would be required to prove this.

Evidence has shown that $\mathrm{UCN}$ protects some neurons via activation of the $\mathrm{CRF}_{1}$ subtype $[5,6]$, whilst activation of $\mathrm{CRF}_{2}$ sites has been cited as important $[10,15]$. The possibility that UCN can 'rescue' damaged cells has been postulated in some studies, especially cardiac myocytes [10] and the heart ex vivo $[11,16]$. We are unclear as to the precise mechanism by which UCN I exerts its protective effect. Our unpublished data indicates that UCN I treatment leads to a preservation or restoration of $\mathrm{TH}+$ cells in the SNc. Whether this is the result of cytoprotection, such as might occur due to an anti-inflammatory action, or a stimulation of neurogenesis remains to be determined. One possibility could be that UCN I might reduce the massive astrogliosis which arises in the $\mathrm{SNc}$ as a result of LPS toxicity [17]. Additionally, the potential contribution of the SNc relative to the ventral tegmental area in restoring nigrostriatal function is also unclear, although we intend to investigate this.

In summary, our data constitutes the first report of a restoration of key indicators of nigrostriatal damage in a neuroinflammatory model of PD after the lesion has become established by a molecule known to have antiinflammatory properties [7]. Although activation of the HPA axis by a CRF agonist might have potentially deleterious side effects, evidence suggests that these may be averted. Thus, CRF and UCN both reduced weight gain in rodents but CRF was much more effective than UCN in this respect and only CRF produced effects consistent with increased sympathetic activity[18]. In order to achieve substantial therapeutic relevance a means by which central $\mathrm{CRF}_{1}$ sites can be activated is clearly essential as may be refinement to ensure an appropriate pharmacological response. While UCN is a relatively large molecule with poor blood brain barrier penetration, recently small, lippophillic, $\mathrm{CRF}_{1}$ selective antagonists have become available and CRF receptor pharmacology is a rapidly expanding field. As such we consider it highly likely that $\mathrm{CRF}_{1}$ agonists will become available offering new possibilities in the study of UCN mediated neuroprotection as well as being of potential therapeutic value in PD.

\section{Abbreviations}

Dopamine (DA), corticotrophin releasing factor (CRF), hypothalamopituitary-adrenal (HPA), lipopolysaccaride (LPS), Parkinson's disease (PD), tyrosine hydroxylase $(\mathrm{TH})$, urocortin (UCN).

\section{Competing interests}

The author(s) declare that they have no competing interests.

\section{Authors' contributions}

$\mathrm{AA}, \mathrm{AH}, \mathrm{CSB}$ and PSW were responsible for the planning and actual experimentation involved in this study. RL contributed to the interpretation of the data and writing of the manuscript.

\section{Acknowledgements}

AA was supported by a doctoral award from the New University of Amman, Amman, Jordan.

\section{References}

I. Vaux DL, Korsmeyer SJ: Cell death in development. Cell 1999, 96:245-254

2. Gandhi S, Wood NW: Molecular pathogenesis of Parkinson's disease. Hum Mol Genet 2005, I4:2749-2755.

3. Block ML, Zecca L, Hong J-S: Microglia-mediated neurotoxicity: Uncovering the molecular mechanisms. Nature Neurosci 2007, 8:57-69.

4. Whitton PS: Inflammation as a potential causative factor in the aetiology of Parkinsons disease. Br J Pharmacol 2007 in press.

5. Pederson WA, Wan R, Zhang P, Mattson MP: Urocortin, but not urocortin II, protects cultured hippocampal neurons from oxidative and excitotoxic cell death via corticotropin-releasing hormone receptor type I. J Neuroscience 2002, 22:404-4I2.

6. Facci L, Stevens DA, Pangallo M, Franceschini D, Skaper SD, Strijbos PJLM: Corticotropin-releasing factor (CRF) and related peptides confer neuroprotection via type I CRF receptors. Neuropharmacology 2003, 45:623-636.

7. Gonzalez-Rey E, Fernandez-Martin A, Chomy A, Delgado M: Therapeutic effect of urocortin and adrenomedullin in a murine model of Crohn's disease. Gut 2006, 55:824-32.

8. Biggs CS, Abuirmeileh A, Locke IC, Knight RA, Chowdrey HS, Whitton PS: Urocortin attenuates key indicators of nigrostriatal pathway destruction in a rat hemiparkinsonian model. Proc Brit Pharm Soc 2006 [http://www.pa2online.org/abstracts/ Vol3lssue4abst 162P.pdf].

9. Lewis K, Li C, Perrin MH, Blount A, Kunitake KS, Donaldson C, Vaughan J, Reyes TM, Gulyas J, Fischer W, Bilezikjian L, Rivier L, Sawachenko PE, Vale WW: Identification of urocortin III, an additional member of the corticotropin-releasing factor (CRF) family with high affinity for the CRF2 receptor. Proc Natl Acad Sci 200I, 98:7570-7575.

10. Brar BK, Jonassen AK, Stephanou A, Santilli A, Railson J, Knight RA, Yellon DM, Latchman DS: Urocortin protects against ischemic and reperfusion injury via a MAPK-dependent pathway. J Biol Chem 2000, 275:8508-85I4.

II. Brar BK, Railson J, Stephanou A, Knight RA, Latchman DS: Urocortin increases the expression of heat shock protein 90 in rat cardiac myocytes in a MEKI/2-dependent manner. J Endocrinol 2002, I 72:283-293. 
12. Biggs CS, Fowler LJ, Pearce BR, Whitton PS: Regional effects of sodium valproate on extracellular concentrations of 5hydroxytryptamine, dopamine and their metabolites in the rat brain: An in vivo microdialysis study. J Neurochem 1992, 59:1702-1708.

13. Block ML, Hong J-S: Microglia and inflammation-mediated neurodegeneration: Multiple triggers with a common mechanism. Progress in Neurobiol 2005, 76:77-98.

14. Abuirmeileh A, Biggs CS, Lever R, Whitton PS: Urocortin reverses Parkinsonian like effects of intra-nigral lipopolysaccaride injection. Proc Brit Pharm Soc 2007 [http://www.pa2online.org/ abstracts/Vol4lssue2abst I56P.pdf].

15. Intekhad-Alam NY, Chowdrey HS, Knight RA, Locke IC: A CRF family peptide protects a human chondrocyte cell line against apoptosis. Osteoarthr Cartilage 2004, I 2(Suppl B): 07.

16. Scarabelli TM, Pasini E, Stephanou A, Comini L, Curello S, Raddino R, Ferrari R, Knight RA, Latchman DS: Urocortin promotes hemodynamic and bioenergetic recovery and improves cell survival in the isolated rat heart exposed to ischemial reperfusion. I Am Coll Cardiol 2002, 40:155-16I.

17. Hirsch EC, Hunot S, Hartmann A: Neuroinflammatory processes in Parkinson's disease. Parkinsonian Relat Disord 2005, II ISuppll I):S9-SI5.

18. Oki Y, Sasano H: Localization and physiological roles of urocortin. Peptides 2004, 25: 1745-1749.

Publish with Bio Med Central and every scientist can read your work free of charge

"BioMed Central will be the most significant development for disseminating the results of biomedical research in our lifetime. "

Sir Paul Nurse, Cancer Research UK

Your research papers will be:

- available free of charge to the entire biomedical community

- peer reviewed and published immediately upon acceptance

- cited in PubMed and archived on PubMed Central

- yours - you keep the copyright

Submit your manuscript here:

http://www.biomedcentral.com/info/publishing_adv.asp
BiolMedcentral 